\title{
Evaluation of Efficacy of Coenzyme Q10 as an Adjunct to Nonsurgical Periodontal Therapy and Its Effect on Crevicular Superoxide Dismutase in Patients with Chronic Periodontitis
}

\author{
Swagat Pranam ${ }^{1}$ Pooja Palwankar ${ }^{1} \quad$ Ruchi Pandey ${ }^{1} \quad$ Anjana Goyal ${ }^{2}$ \\ ${ }^{1}$ Department of Periodontology, Manav Rachna Dental College, \\ Haryana, India \\ 2Department of Biochemistry, Manav Rachna Dental College, \\ Haryana, India \\ Address for correspondence Swagat Pranam, MDS, Department \\ of Periodontology, Manav Rachna Dental College, Faridabad, \\ Haryana 121001, India (e-mail: drswagatpranam@gmail.com). \\ Pooja Palwankar, MDS, Department of Periodontology, Manav \\ Rachna Dental College, Faridabad, Haryana 121001, India \\ (e-mail: pooja.mrdc@mrei.ac.in)
}

Eur J Dent:2020;14:551-557

\begin{abstract}
Keywords

- chronic periodontitis

- coenzyme Q10

- ELISA

- gingival crevicular

fluid

- superoxide dismutase
\end{abstract}

Objectives To assess the efficacy of coenzyme Q10 (CoQ10) as an adjunct to nonsurgical periodontal therapy and its effect on superoxide dismutase (SOD) in gingival crevicular fluid (GCF) in patients with chronic periodontitis (CP).

Materials and Methods A total of 16 patients aged between 30 and 50 years having mild to moderate $\mathrm{CP}$ of both sexes having pocket depth of 5 to $7 \mathrm{~mm}$ in four nonadjacent interproximal sites were selected. The sites were randomized and divided into treatment and control groups. CoQ10 and a placebo gel were administered in the treatment and control sites, respectively, at baseline after scaling and root planing (SRP). GCF was collected using microcapillary method at baseline and 3 months and was assessed for SOD using enzyme-linked immunosorbent assay reader at $450 \mathrm{~nm}$ wavelength. Probing pocket depth, gingival index, and plaque index were assessed at baseline, 1 month, and 3 months, respectively.

Statistical analysis For each assessment point, data were statistically analyzed using Student's $t$-test and paired $t$-test. Level of significance was set at $p<0.05$.

Results On intergroup comparison, there was no statistically significant difference between the clinical parameters of both the groups at all the time intervals $(p>0.05)$, but there was a significant increase in the level of SOD in the test group $(p>0.05)$ compared with the control group at 3 months.

Conclusions Adjunctive use of CoQ10 with SRP can boost the antioxidant concentration, but it is not superior to SRP in the treatment of CP.

\section{Introduction}

Periodontitis is a disease process which results in the destruction of the periodontium. The tissue destruction is believed to be the result of loss of homeostatic balance between reactive oxygen species (ROS) and antioxidant defense system. ${ }^{1}$

ROS are a group of oxygen-derived free radicals (ODFRs), which act by oxidizing biomolecules vital to cell and tissue

DOI https://doi.org/

10.1055/s-0040-1716596

ISSN $1305-7456$. function. ${ }^{2,3}$ An antioxidant is a substance which delays the oxidation of any oxidizable substrate. They protect the biological systems by sequestrating the free catalytic metal ions which aid in ROS formation. ${ }^{2}$ In a normal healthy environment, there is a balance between the activity of ROS and antioxidant defense system. In reduction of capability of antioxidants or increase in ROS activity or in ROS production, the balance tilts in favor of ROS which results in oxidative stress and vice versa ( - Fig. 1 ). 


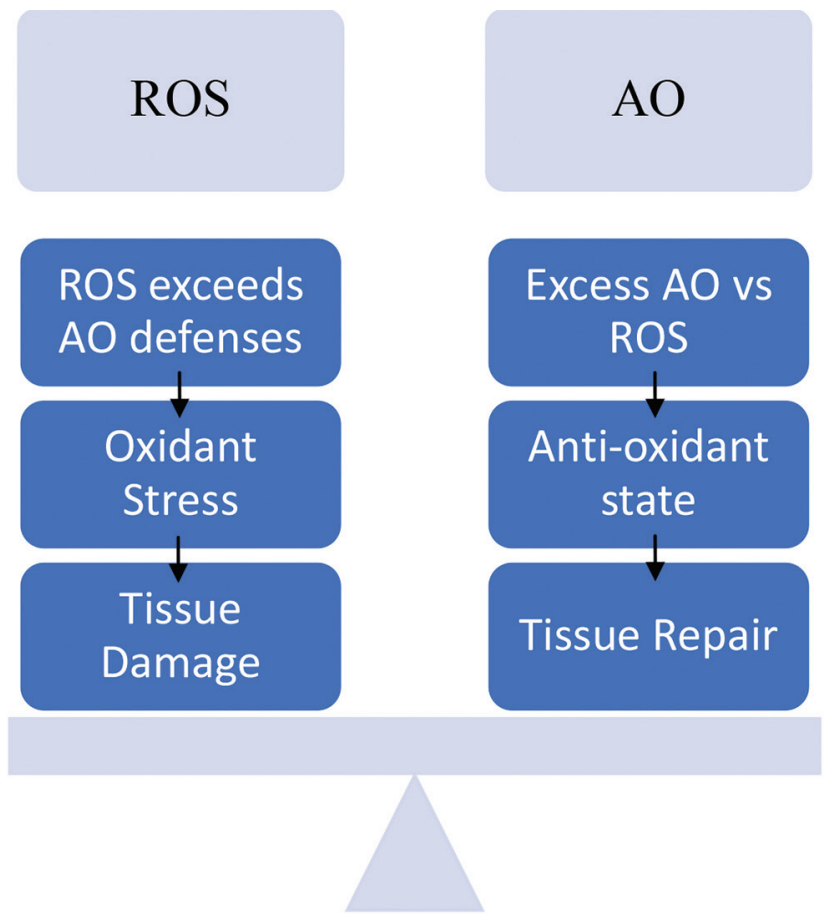

Fig. 1 The effects of shift in equilibrium between the reactive oxygen species (ROS) and antioxidant species (AO).

Human body has both nonenzymatic and enzymatic antioxidants to counter ROS. The most important intracellular enzymes which protect cells and tissues from the ODFRs are superoxide dismutase (SOD), glutathione peroxidase (GPx), and catalase (CAT). ${ }^{4}$

SOD is the first line of antioxidant defense mechanism. It catalyzes the dismutation of two molecules of superoxide anion $\left(\mathrm{O}_{2}\right)$ to hydrogen peroxide and molecular oxygen, consequently rendering the potentially harmful superoxide anion less hazardous.

Coenzyme Q10 (CoQ10) is a well-established antioxidant which helps in regeneration of other antioxidants, stimulation of cell growth, and inhibition of cell death. ${ }^{5}$ CoQ10 deficiency may be associated with periodontal diseases and its administration to periodontal tissues may control its damage. Topical administration to the gingiva as a sole treatment may decrease gingival crevicular fluid (GCF) flow, probing depths, and improve clinical gingival attachment. ${ }^{6}$

Being the first antioxidant defense enzyme, SOD in GCF is a useful indicator of periodontal disease activity and it has been reported that periodontal disease is associated with increased total oxidative status and decreased levels of SOD which is restored to normal level after periodontal therapy. ${ }^{7}$ Hence, this study is being done to evaluate the efficacy of CoQ10 as an adjunct to scaling and root planing (SRP) and its effect on SOD in GCF.

\section{Materials and Methods}

\section{Study Groups and Design}

This study was a 3-month randomized controlled split mouth study which was designed and conducted in the department of periodontology and approved by the institutional ethics committee. A written informed consent was taken from the subjects before enrolling them into the study. The study enrolled 16 patients aged between 30 and 50 years having mild to moderate chronic periodontitis (CP) of both sexes having pocket depth of 5 to $7 \mathrm{~mm}$ in four nonadjacent interproximal sites. The selected sites underwent computer randomization for selection to either one of the test groups. Subjects with no relevant medical history and no history of tobacco usage were included in the study. Subjects with a history of taking vitamin supplements, regular use of mouthwash and antibiotic medication or any form of periodontal therapy in the preceding 6 months, and pregnant and lactating mother were not included in the study. The study was started in July 2018 and ended in December 2018.

After enrollment, GCF samples were collected at baseline before recording of clinical parameters which included Turesky-Gilmore-Glickman's modification of the Quigley and Hein index, Loe and Silness gingival index (GI), probing pocket depth (PPD), and clinical attachment level. After data collection, the selected sites underwent SRP, pockets were dried with paper points, then either of the gel as determined was applied to the selected sites directly with an intrasulcular applicator tip and then withdrawn, while continuing to extrude the material, till the superior portion of the pocket. Oral hygiene instructions were given, which included avoidance of dental floss or interdental aids or use of any mouth rinses and modified bass brushing technique was standardized for all the patients. Subjects were then recalled after 1 month for recording of clinical parameters and after 3 months for recording of both clinical and biochemical parameters ( - Fig. 2 ).

\section{Gel Dispensing}

CoQ10 gel (Perio $\left.Q_{10}\right)$ is manufactured by Perio Inc, United States and placebo gel was packed and provided by the manufacturer. The CoQ10 and the placebo gel were each loaded in a different $2 \mathrm{~mL}$ syringe with an intrasulcular applicator tip which was masked with a black tape by the study coordinator and labeled as gel A and B. At the end of the study, decoding was done to compare and relate the data by the study coordinator.

\section{GCF Collection and SOD Level Estimation}

GCF was collected from the selected sites with the help of calibrated capillary micropipettes and stored in Eppendorf tube at $80 \mathrm{C}$ for estimation of SOD levels.

The SOD levels were analyzed using an enzyme-linked immunosorbent assay reader.

\section{Statistical Analysis}

Data that were collected were evaluated using means and standard deviations (SDs) of the measurements per group for statistical analysis (SPSS 22.00 for windows; SPSS Inc., Chicago, United States). For each assessment point, data were statistically analyzed using Student's $t$-test and paired $t$-test. Level of significance was set at $p<0.05$. 


\section{ENROLLMENT}

Assessed for eligibility 88 sites (22 subjects)

According to inclusion and exclusion criteria

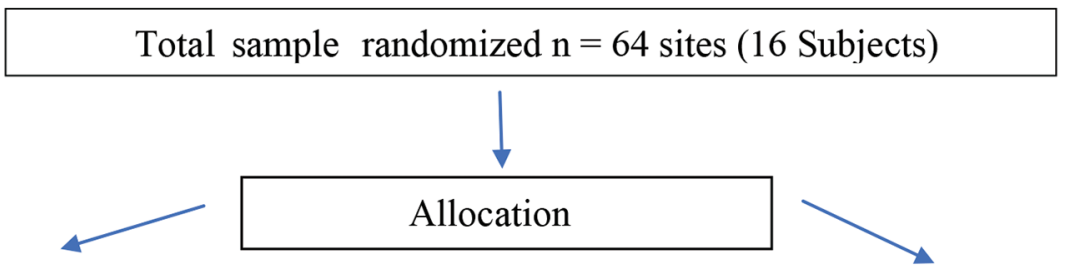

(Test group 1) $\mathbf{n}=32$ sites

(Test group 2) $n=32$ sites

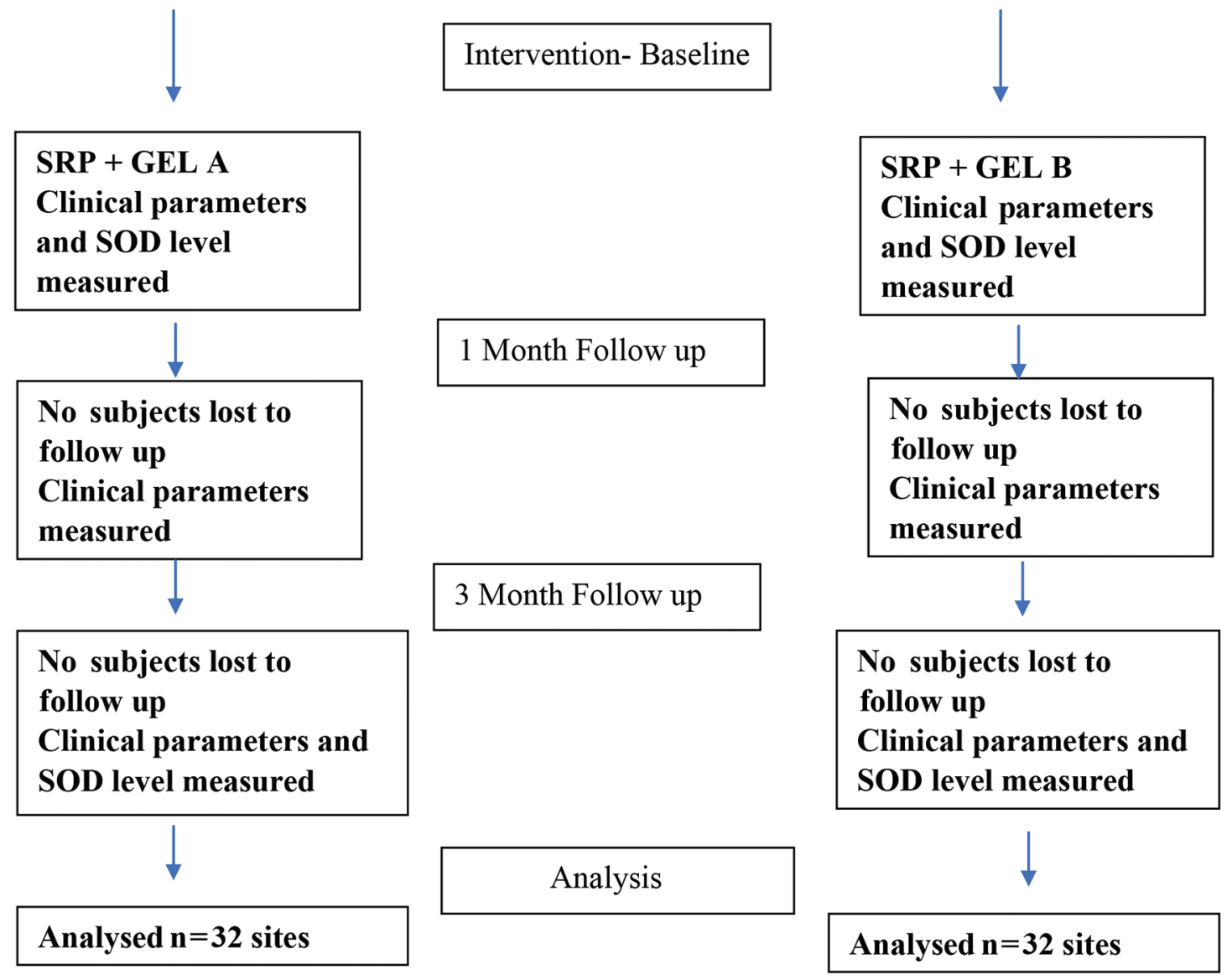

Fig. 2 Study design. SOD, superoxide dismutase; SRP, scaling and root planing.

\section{Results}

A total of 16 subjects, 7 females and 9 males, with an average mean age of 42 years were selected based on the inclusion and exclusion criteria. Four nonadjacent interproximal sites from each subject having pocket depth of 5 to $7 \mathrm{~mm}$ were randomized into two treatment groups and were assessed for the clinical parameters (plaque index [PI], GI, PPD, and clinical attachment level) and the biochemical parameter (SOD). 
Table 1 Comparison of clinical and biochemical parameters of the study groups at different time intervals

\begin{tabular}{|c|c|c|c|c|c|c|c|}
\hline \multirow{3}{*}{$\begin{array}{l}\text { Groups } \\
\text { Group A } \\
\text { (CoQ10) }\end{array}$} & \multicolumn{2}{|c|}{ Comparison } & \multirow{2}{*}{$\begin{array}{l}\text { Mean } \\
2.30\end{array}$} & \multirow{2}{*}{$\begin{array}{l}\text { SD } \\
0.61\end{array}$} & \multirow{2}{*}{$\begin{array}{l}\text { Change from baseline } \\
\text { to } 3 \mathrm{mo}( \pm S D) \\
1.7 \pm 0.51\end{array}$} & \multirow{2}{*}{$\begin{array}{l}t \text {-Value } \\
1.630\end{array}$} & \multirow{2}{*}{$\begin{array}{l}p \text {-Value } \\
0.0001^{\mathrm{a}, \mathrm{c}}\end{array}$} \\
\hline & \multirow[t]{3}{*}{$\mathrm{PI}$} & Baseline & & & & & \\
\hline & & $1 \mathrm{mo}$ & 0.66 & 0.26 & & & \\
\hline & & $3 \mathrm{mo}$ & 0.60 & 0.16 & & & \\
\hline & \multirow[t]{3}{*}{ Gl } & Baseline & 1.79 & 0.46 & \multirow[t]{3}{*}{$1.20 \pm 0.45$} & \multirow[t]{3}{*}{2.175} & \multirow[t]{3}{*}{$0.0001^{\mathrm{a}, \mathrm{c}}$} \\
\hline & & $1 \mathrm{mo}$ & 0.64 & 0.29 & & & \\
\hline & & $3 \mathrm{mo}$ & 0.59 & 0.23 & & & \\
\hline & \multirow[t]{3}{*}{ PPD } & Baseline & 5.47 & 0.56 & \multirow[t]{3}{*}{$1.16 \pm 0.45$} & \multirow[t]{3}{*}{1.000} & \multirow[t]{3}{*}{$0.0001^{\mathrm{a}, \mathrm{c}}$} \\
\hline & & $1 \mathrm{mo}$ & 4.31 & 0.47 & & & \\
\hline & & $3 \mathrm{mo}$ & 4.31 & 0.47 & & & \\
\hline & \multirow[t]{3}{*}{ CAL } & Baseline & 6.13 & 0.61 & \multirow[t]{3}{*}{$1.25 \pm 0.51$} & \multirow[t]{3}{*}{0.763} & \multirow[t]{3}{*}{$0.0001^{\mathrm{a}, \mathrm{c}}$} \\
\hline & & $1 \mathrm{mo}$ & 4.88 & 0.55 & & & \\
\hline & & $3 \mathrm{mo}$ & 4.88 & 0.55 & & & \\
\hline & \multirow[t]{3}{*}{ SOD } & Baseline & 230.33 & 36.41 & \multirow[t]{3}{*}{$7,238.65 \pm 1,025.23$} & \multirow[t]{3}{*}{8.483} & \multirow[t]{3}{*}{$0.0001^{\mathrm{a}, \mathrm{c}}$} \\
\hline & & $1 \mathrm{mo}$ & - & - & & & \\
\hline & & $3 \mathrm{mo}$ & $7,468.97$ & $1,033.44$ & & & \\
\hline \multirow{15}{*}{$\begin{array}{l}\text { Group B } \\
\text { (Placebo) }\end{array}$} & \multirow[t]{3}{*}{$\mathrm{PI}$} & Baseline & 2.28 & 0.74 & \multirow[t]{3}{*}{$1.43 \pm 0.55$} & 1.868 & $0.0001^{\mathrm{a}, \mathrm{c}}$ \\
\hline & & $1 \mathrm{mo}$ & 0.92 & 0.37 & & & \\
\hline & & $3 \mathrm{mo}$ & 0.85 & 0.37 & & & \\
\hline & Gl & Baseline & 1.81 & 0.51 & $0.96 \pm 0.32$ & 1.735 & $0.0001^{\mathrm{a}, \mathrm{c}}$ \\
\hline & & $1 \mathrm{mo}$ & 0.93 & 0.32 & & & \\
\hline & & $3 \mathrm{mo}$ & 0.85 & 0.39 & & & \\
\hline & PPD & Baseline & 5.13 & 0.42 & $1.09 \pm 0.29$ & 0.747 & $0.0001^{\mathrm{a}, \mathrm{c}}$ \\
\hline & & $1 \mathrm{mo}$ & 4.03 & 0.31 & & & \\
\hline & & $3 \mathrm{mo}$ & 4.03 & 0.31 & & & \\
\hline & CAL & Baseline & 6.16 & 0.62 & $1.19 \pm 0.39$ & 0.565 & $0.0001^{\mathrm{a}, \mathrm{c}}$ \\
\hline & & $1 \mathrm{mo}$ & 4.97 & 0.65 & & & \\
\hline & & $3 \mathrm{mo}$ & 4.97 & 0.65 & & & \\
\hline & SOD & Baseline & 229.44 & 39.93 & $5,975.28 \pm 803.24$ & 6.468 & $0.0001^{\mathrm{a}, \mathrm{c}}$ \\
\hline & & $1 \mathrm{mo}$ & - & - & & & \\
\hline & & $3 \mathrm{mo}$ & $5,975.28$ & 770.33 & & & \\
\hline $\begin{array}{l}\text { Group A v } \\
\text { (p-value) }\end{array}$ & $\begin{array}{l}\text { p B } \\
\text { ison }\end{array}$ & $\begin{array}{l}\text { Baseline } t \\
\text { intergrou }\end{array}$ & o change & 1 to $3 \mathrm{~m}$ & nge intergroup & $\begin{array}{l}\text { Baseline } \\
\text { intergrc }\end{array}$ & 3 mo change \\
\hline $\mathrm{PI}$ & & $0.066^{\mathrm{b}}$ & & $0.213^{b}$ & & $0.110^{\mathrm{b}}$ & \\
\hline $\mathrm{Gl}$ & & $0.079^{b}$ & & $0.903^{b}$ & & $0.210^{\mathrm{b}}$ & \\
\hline PPD & & $0.458^{b}$ & & 1.0 & & $0.321^{\mathrm{b}}$ & \\
\hline CAL & & $0.553^{b}$ & & $1.00^{\mathrm{b}}$ & & $0.448^{b}$ & \\
\hline SOD & & - & & - & & $0.0001^{\mathrm{a}}$ & \\
\hline
\end{tabular}

Abbreviations: CAL, clinical attachment level; CoQ10, coenzyme Q10; GI, gingival index; PI, plaque index; PPD, probing pocket depth; SD, standard deviation; SOD, superoxide dismutase.

aHighly significant.

'Nonsignificant, Student's t-test applied.

${ }^{c} p$-Value significant at $<0.05$.

\section{Clinical Parameters}

Results of clinical parameters of both the groups are reported in - Table 1. Clinical parameters (PI, GI, PPD, and clinical attachment level) were recorded at baseline, 1 month, and 3 months interval. Statistical analysis was expressed using mean, $\mathrm{SD}, t$-value, and $p$-value.

There was a change in PI from baseline to 3 months in both the groups. Group A showed mean change of
$1.7 \mathrm{~mm}(\mathrm{SD}=0.51)$ and Group B showed mean change of $1.43 \mathrm{~mm}(\mathrm{SD}=0.55)$. The changes were clinically significant, but on intergroup comparison, it was not statistically significant.

GI also showed clinically significant changes from baseline to 3 months in both the groups. Group A showed mean change score of $1.20(S D=0.45)$ and Group B showed mean change score of $0.96(S D=0.32)$ from baseline to 3 months, 
but on intergroup comparison, it was found to be not statistically significant.

PPD and clinical attachment level both showed clinically significant change from baseline to 1 month, but there was no change in the levels between 1 month and 3 months. Mean probing depth at baseline for Group A was $5.47 \mathrm{~mm}$ $(\mathrm{SD}=0.56)$, and at 1 month, it was $4.31 \mathrm{~mm}(\mathrm{SD}=0.47)$ and at 3 months, it remained at $4.31 \mathrm{~mm}(\mathrm{SD}=0.47)$. For Group B, the mean probing depth at baseline was $5.13 \mathrm{~mm}(\mathrm{SD}=0.42$ ), and at 1 month, it was $4.03 \mathrm{~mm}(\mathrm{SD}=0.31)$ and at 3 month, it was $4.03 \mathrm{~mm}(\mathrm{SD}=0.31)$. Clinical attachment level for Group A was $6.13 \mathrm{~mm}(\mathrm{SD}=0.61)$ at baseline and $4.88 \mathrm{~mm}(\mathrm{SD}=$ $0.55)$ and $4.88 \mathrm{~mm}(\mathrm{SD}=0.55)$ at 1 month and 3 months, respectively. For Group B, it was $6.16 \mathrm{~mm}(\mathrm{SD}=0.62)$ at baseline, $4.97 \mathrm{~mm}(\mathrm{SD}=0.65)$ and $4.97 \mathrm{~mm}(\mathrm{SD}=0.65)$ at 1 month and 3 months, respectively. On intergroup comparison, the results were not statistically significant (-Fig. $\mathbf{3}$ ).

\section{Biochemical Parameters}

SOD levels in GCF were measured at baseline and 3 months. Both the groups showed an increase in SOD level from baseline to 3 months. At baseline for Group A, the sod level was 230.33 $\mathrm{pg} / \mathrm{mL}(\mathrm{SD}=36.41$ ) and for Group B, it was $229.44 \mathrm{pg} / \mathrm{mL}$ $(\mathrm{SD}=39.93)$. The sod levels increased after 3 months to $7,468.97 \mathrm{pg} / \mathrm{mL}(\mathrm{SD}=1,033.44)$ for Group A and to 5,975.28 $\mathrm{pg} / \mathrm{mL}(\mathrm{SD}=770.33$ ) for Group B. The intergroup comparative values showed statistically significant difference between the groups (-Fig. 4 ).

\section{Discussion}

Periodontal diseases result in release of ROS which cause increase in oxidative stress and loss of redox balance which results in tissue destruction. To combat the increased ROS, body in defense releases antioxidants which helps in detoxification of ROS in less harmful substances. ${ }^{8}$ Enzymatic antioxidants such as SOD, CAT, and GPx form the first line of defense in the entire antioxidant defense grid. ${ }^{9}$ SOD is a primary enzyme which scavenges oxygen free radical, hence it is an important antioxidant enzyme that protects tissues against oxidative injury resulting from oxidative stress. ${ }^{10}$ Antioxidant therapy for treatment of periodontitis has given positive results as stated in a systemic review by Castro et al. ${ }^{11}$ CoQ10, which is also known as ubiquinone, because of its ubiquitous presence, is an antioxidant enzyme and has been studied widely for its effect in treatment of periodontal disease. ${ }^{12-20}$

In the present study, an attempt had been made to evaluate the efficacy of CoQ10 in reduction of clinical parameters (GI, PI, PPD, and CAL) and its effect on SOD in GCF as an adjunct to Phase 1 periodontal therapy.

Previous studies conducted with CoQ10 by various authors ${ }^{12-20}$ did not use any biochemical parameter to assess its efficacy and the results were assessed by the clinical parameters alone.

The clinical parameters in our study showed improvements in both the test and the control groups, and the results showed statistically significant changes, but on intergroup comparison, the changes were not significant. These findings are similar to the study by Hans et al $(2012)^{5}$ wherein the application of CoQ10 gel along with SRP and SRP alone after 6 weeks showed no statistically significant intergroup changes.

In similar studies by Sharma et al (2016), ${ }^{13}$ Attia et al (2016), ${ }^{14}$ and Roopa et al (2014), ${ }^{15}$ it was found that there were some clinical changes in the group treated with CoQ10, but it was not statistically significant than the control group. The clinical change could be due to immune enhancing property of CoQ10, but it was not statistically significant due to the fact that effect of CoQ10 locally may not be enough to provide a significant change than SRP. The substantivity of the CoQ10 has not yet been ascertained

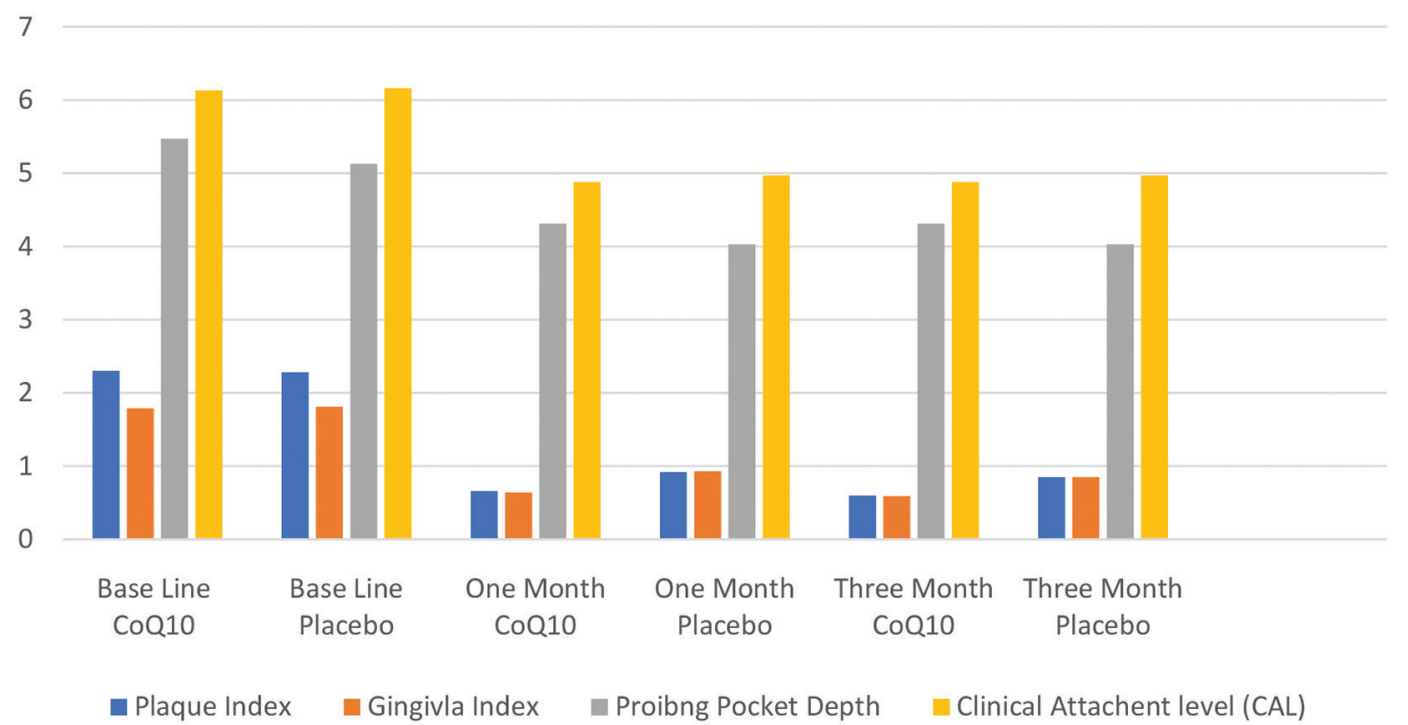

Fig. 3 Clinical parameters. 


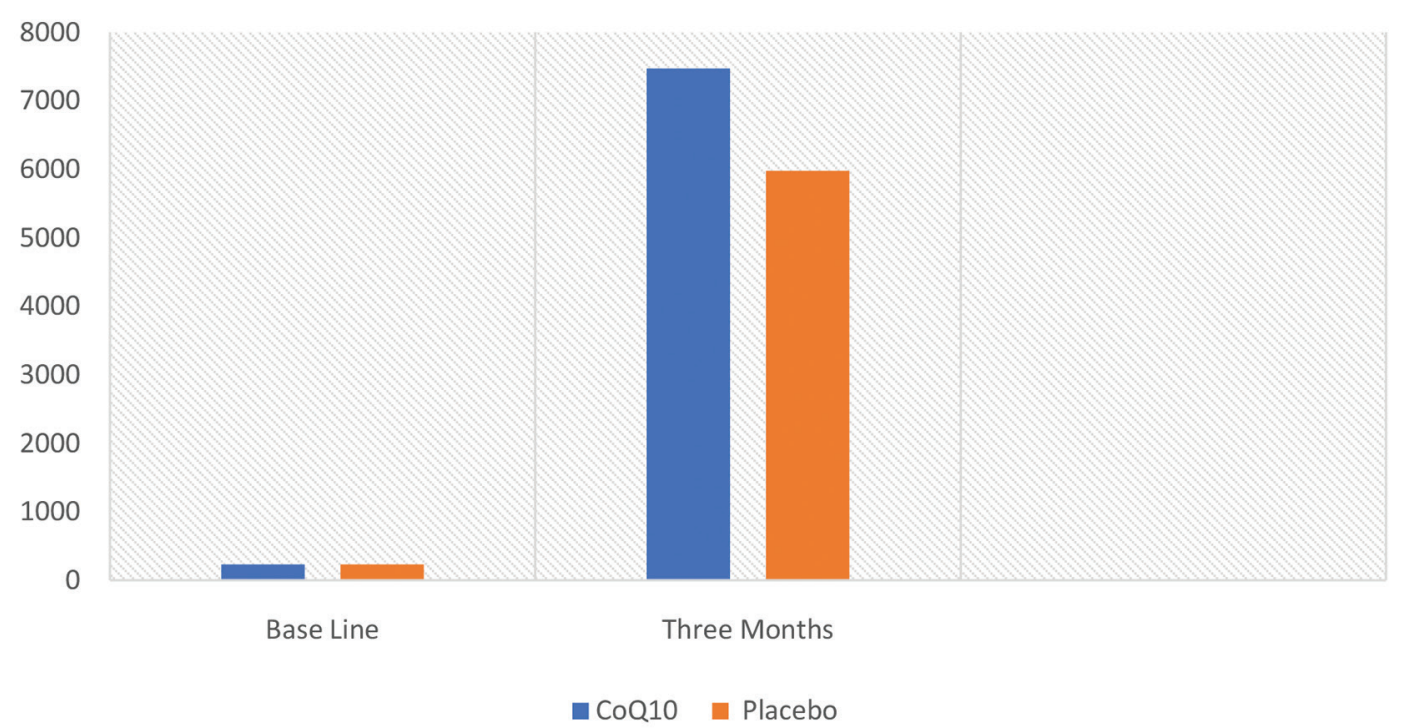

Fig. 4 Bio chemical parameter (SOD level).

and proper retention of the gel could be an issue in the periodontal pocket; hence, a gel-based application of CoQ10 would not render the necessary effect as shown by Shaheen et al $(2020)^{16}$ wherein nanoformulation of CoQ10 showed positive results in the treatment of moderate periodontitis.

Results contrary to the study has also been shown by Sale et al (2014), ${ }^{17}$ Raut and Sethi (2016), ${ }^{18}$ and Manthena et al (2015) ${ }^{19}$ wherein they found positive changes in the treatment group for periodontitis patient over the control group, but these studies did not have a long follow-up period or had used oral supplements in their study. The study period for Sale et al (2014) $)^{17}$ and Raut and Sethi (2016) ${ }^{18}$ was a 4 -week/1-month period and Manthena et $\mathrm{al}^{19}$ had used CoQ10 as oral supplement. Chug and Shukla (2020) ${ }^{20}$ corroborated the same as found by this study that CoQ10 has no beneficial effect in the treatment of periodontitis and earlier studies that supported the notion that CoQ10 had beneficial effects were studies of short duration.

The change in level of SOD was evident as the tissue returned from diseased state to healthy state in both the treatment and the control groups and the findings were consistent with the findings of Karim et al (2012) and Elavarasu et al (2016).

On intergroup comparison between the CoQ10 group and the placebo group. There was a statistically significant increase in the CoQ10 group because of the immune enhancing activity of CoQ10 which has resulted in the increase of SOD.

Extrapolating the results of previous study and combining the findings of the present study, both the groups showed improvement in clinical parameters over the 3-month study period. The use of CoQ10 as an adjunct to SRP showed improvement in the clinical parameters, but it was statistically not better than SRP alone. This may be attributed to deficiency of CoQ10 in the periodontium. This is in accordance with the studies done by Nakamura et $a .^{22}$ The SOD levels were increased significantly in the CoQ10 group compared with the placebo group due to the fact that CoQ10 acts as a bioenergizer and is capable of regenerating other antioxidants.

\section{Limitation}

The study could have used microbiological analysis to ascertain the specific periodontal pathogens that are affected with the use of an antioxidant. Longer duration of the study and the presence of radiographic analysis would have given a clear assessment of the results.

\section{Conclusions}

The study concluded that the adjunctive use of CoQ10 with SRP can boost the antioxidant concentration, but it is not superior to SRP in improving the clinical parameters following the treatment of $\mathrm{CP}$ patients. Longitudinal studies using a larger sample size are required to ascertain the effect of CoQ10 as an adjunct to scaling root planing in the treatment of $\mathrm{CP}$.

\section{Funding \\ None. \\ Conflict of Interest \\ None declared.}

\section{References}

1 Chapple IL, Matthews JB. The role of reactive oxygen and antioxidant species in periodontal tissue destruction. Periodontol 2000 2007;43(1):160-232

2 Waddington RJ, Moseley R, Embery G. Reactive oxygen species: a potential role in the pathogenesis of periodontal diseases. Oral Dis 2000;6(3):138-151 
3 Palwankar P, Rana M, Arora K, Deepthy C. Evaluation of non-surgical therapy on glutathione levels in chronic periodontitis. Eur J Dent 2015;9(3):415-422

4 Diab-Ladki R, Pellat B, Chahine R. Decrease in the total antioxidant activity of saliva in patients with periodontal diseases. Clin Oral Investig 2003;7(2):103-107

5 Hans M, Prakash S, Gupta S. Clinical evaluation of topical application of Perio Q gel (coenzyme Q(10)) in chronic periodontitis patients. J Indian Soc Periodontol 2012;16(2):193-199

6 Hanioka T, Tanaka M, Ojima M, Shizukuishi S, Folkers K. Effect of topical application of coenzyme Q10 on adult periodontitis. Mol Aspects Med 1994;15(Suppl):s241-s248

7 Karim S, Pratibha PK, Kamath S, et al. Superoxide dismutase enzyme and thiol antioxidants in gingival crevicular fluid and saliva. Dent Res J (Isfahan) 2012;9(3):266-272

8 Dahiya P, Kamal R, Gupta R, Bhardwaj R, Chaudhary K, Kaur S. Reactive oxygen species in periodontitis. J Indian Soc Periodontol 2013;17(4):411-416

9 Ighodaro OM, Akinloye OA. First line defence antioxidants-superoxide dismutase (SOD), catalase (CAT) and glutathione peroxidase (GPX): their fundamental role in the entire antioxidant defence grid. Alexandria J. Med. 2018;54(4):287-293

10 Coutinho AO, Sanikop S. A comparative analysis of superoxide dismutase activity levels in gingiva and gingival crevicular fluid in patients with chronic periodontitis and periodontally healthy controls. Free Radic Biol Med 2012;2(4):19-25

11 Castro MM, Duarte NN, Nascimento PC, et al. Antioxidants as adjuvants in periodontitis treatment: a systematic review and meta-analysis. Oxid Med Cell Longev 2019;2019:9187978

12 Kadir AK, Rabbi AA, Rahman MM. Coenzyme Q10: a new horizon in the treatment of periodontal diseases. Int Dent J Stud Res 2017;5:1-6

13 Sharma V, Gupta R, Dahiya P, Kumar M. Comparative evaluation of coenzyme Q10-based gel and $0.8 \%$ hyaluronic acid gel in treatment of chronic periodontitis. J Indian Soc Periodontol 2016;20(4):374-380

14 Attia AM, Edrees MF, Alghriany A. Clinical and immunological evaluation of coenzyme Q10 as an adjunct to nonsurgical periodontal therapy in chronic periodontitis patients. J Periodontal Med Clin Prac. 2016;03:128-140

15 Roopa DA, Gupta R, Gupta I, Chauhan S, Pandey A, Sharma NK. Clinical evaluation of topical application of CNBC gel (coenzyme Q10) in chronic periodontitis patients. J Dent Res Updates. 2014;1(1):13-17

16 Shaheen MA, Elmeadawy SH, Bazeed FB, Anees MM, Saleh NM. Innovative coenzyme Q10-loaded nanoformulation as an adjunct approach for the management of moderate periodontitis: preparation, evaluation, and clinical study. Drug Deliv Transl Res 2020;10(2):548-564

17 Sale ST, Parvez H, Yeltiwar RK, Vivekanandan G, Pundir AJ, Jain P. A comparative evaluation of topical and intrasulcular application of coenzyme Q10 (Perio $\mathrm{Q}^{\mathrm{TM}}$ ) gel in chronic periodontitis patients: a clinical study. J Indian Soc Periodontol 2014;18(4):461-465

18 Raut CP, Sethi KS. Comparative evaluation of co-enzyme Q10 and Melaleuca alternifolia as antioxidant gels in treatment of chronic periodontitis: a clinical study. Contemp Clin Dent 2016;7(3):377-381

19 Manthena S, Rao MV, Penubolu LP, Putcha M, Harsha AV. Effectiveness of CoQ10 oral supplements as an adjunct to scaling and root planing in improving periodontal health. J Clin Diagn Res 2015;9(8):ZC26-ZC28

20 Chug A, Shukla S. Placement of Sticky Bone ${ }^{\mathrm{TM}}$ in patients with generalized periodontitis previously treated with coenzyme Q10. J Contemp Dent Pract 2020;21(2):156-160

21 Elavarasu S, Suthanthiran T, Thangavelu A, Alex S, Palanisamy VK, Kumar TS. Evaluation of superoxide dismutase levels in local drug delivery system containing $0.2 \%$ curcumin strip as an adjunct to scaling and root planing in chronic periodontitis: a clinical and biochemical study. J Pharm Bioallied Sci 2016;8(Suppl 1) :S48-S52

22 Littarru GP, Nakamura R, Ho L, Folkers K, Kuzell WC. Deficiency of coenzyme Q10 in gingival tissue from patients with periodontal disease. Proc Natl Acad Sci 1971;68(10):2332-2335 